\title{
PORTOS, PORTAS E PRODUÇÃO: ARQUEOLOGIA DO PODER EM CANANÉIA (SP), SÉCULOS XIX e XX
}

Harbors, doors and production: the Archaeology of Power in Cananéia (São Paulo State), 19th and 20 th centuries

Paulo F. Bava de Camargo ${ }^{1}$

\section{RESUMO}

O objetivo deste artigo é mostrar que, até mesmo em uma localidade periférica a um dos subcentros do capitalismo contemporâneo, ou seja, em Cananéia, distante aproximadamente 300 milhas náuticas do Rio de Janeiro, antiga capital do Brasil, a distribuição das estruturas, edificações e equipamentos no tecido urbano de uma cidade portuária, com especial atenção às casas comerciais, espelhou as modificações das formas de controle da produção e da circulação de mercadorias ocorridas a partir da dispersão do modo de produção capitalista pelo mundo.

Palavras-chave: Arqueologia do Capitalismo, Arqueologia Urbana, Cananéia

\begin{abstract}
The aim of this article is to show that, even in places on the edges of contemporary capitalist sub centers, like Cananéia, distant approximately 300 nautical miles from Rio de Janeiro, ancient capital of Brazil, the spatial distribution of structures, buildings and equipment in the urban net of a harbor city, with special attention to the commercial houses, mirrored the modifications of the forms of control over production and circulation of commodities that have occurred since the spread of the capitalist mode of production throughout the world.
\end{abstract}

Keywords: Archaeology of Capitalism, Urban Archaeology, Cananéia

\section{RESUMEN}

El objetivo de este artículo es mencionar que, incluso en una localidad periférica de uno de los subcentros del capitalismo contemporáneo - en Cananéia, con distancia aproximada de 300 millas náuticas del Rio de Janeiro, antigua capital del Brasil - la distribución de las estructuras, edificaciones y equipamientos en el tejido urbano de una ciudad portuaria, con especial atención a las tiendas comerciales, reflejó las modificaciones de las formas de control de la producción y de la circulación de mercancías realizadas a partir de la dispersión del modo de producción capitalista por el mundo.

Palabras claves: Arqueología del Capitalismo, Arqueología Urbana, Cananéia

\footnotetext{
${ }^{1}$ Pesquisador Colaborador (Pós-Doutorado) - Departamento de História/ Instituto de Filosofia e Ciências Humanas/ Universidade Estadual de Campinas (DH/ IFCH/ UNICAMP). Bolsista da Fundação de Amparo à Pesquisa do Estado de São Paulo (FAPESP) - pfbavac@gmail.com
} 


\section{Introdução}

Este artigo está embasado em um capítulo de minha tese de doutoramento ${ }^{2}$, na qual continuei a desenvolver um tema trabalhado desde o Mestrado (2002): a História do estabelecimento das formas de controle do vale do Ribeira paulista que poderia ser construída a partir da Arqueologia das paisagens marítimas dessa região.

De início, no Mestrado, abordei as edificações, estruturas e equipamentos de defesa militar como o objeto principal da pesquisa, tendo em vista que a materialização do poder absolutista se dava de forma explícita e direta, infligindo o medo do dano físico - ou o próprio dano físico - àquele que ameaçasse o domínio da coroa lusitana. Já no Doutorado, examinando as formas de controle desenvolvidas a partir do Segundo reinado, despontaram as paisagens portuárias como os alvos primordiais para o entendimento desse poder, fundamentalmente econômico e de contornos mais difusos, mas tão ou mais centralizador quanto no período colonial e no Primeiro reinado.

Se, no caso do poder absolutista, tem-se, principalmente - mas não exclusivamente armas e fortificações, coisas localizadas e pontuais que serão apropriadas como bens de interesse arqueológico, com relação à Arqueologia do poder capitalista há um conjunto de coisas dispersas pelo espaço, construindo paisagens que não parecem, à primeira vista, edificações, estruturas e equipamentos destinados à regulação da produção ${ }^{3}$. Como consequência, fez-se necessária uma Arqueologia tanto das ruínas e jazimentos, locus normal da prática arqueológica, quanto de alguns bens que ainda estavam em uso, pois, em verdade, o espaço do capital é o nosso espaço, goste-se ou não disso.

Esse foi o primeiro problema dessa abordagem: tratar objetivamente paisagens com múltiplas apropriações. Ou seja, enxergaram-se, a partir da Arqueologia, elementos materiais que pertenciam ao mundo dos viventes e que possuíam significados diversos e dinâmicos. Remete-se, especificamente, ao fato paradoxal das paisagens portuárias de Cananéia serem determinadas por seu uso atual, mas, também, por serem apropriadas como patrimônio histórico. Assim, se por um lado, edificações, estruturas e equipamentos antigos são usados, desgastados, destruídos, reconstruídos e transformados por aqueles que veem neles um valor funcional, por outro, esses mesmos bens são esvaziados de funcionalidade primária e

\footnotetext{
${ }^{2}$ Intitulada Arqueologia de uma cidade portuária: Cananéia, séculos XIX-XX. Defendida em 2009, no MAEUSP, foi desenvolvida sob a orientação de Maria Cristina M. Scatamacchia. O autor contou com bolsa do CNPq. ${ }^{3}$ Embora o conceito possa ser abrangente, no caso aqui abordado deve-se entender produção como a fabricação de mercadorias.
} 
transfigurados em monumentos que aludem ao antigo, situado este sempre em um passado colonial e escravista por decreto.

Exemplos dessa situação são o monumento a Martim Afonso e o porto Bacharel. O primeiro está na praça principal de Cananéia: foi erguido há mais de 80 anos, com canhões ingleses do final do século XVIII, mas faz alusão à chegada de Martim Afonso, em 1531. Neste caso, é clara a exaltação do ato fundador colonial com objetos que nada têm a ver com o evento em si, apropriados para a homenagem pelo simples fato de serem antigos e/ou representarem o poder metropolitano/europeu. Com relação ao porto Bacharel, essa associação não é tão explícita. Ele ganhou essa denominação em alusão ao bacharel ibérico que teria sido degredado naquela porção do litoral, entre o final do século XV e início do XVI, transformando-se em um potentado local. O uso dessa porção do espaço portuário de Cananéia é, sem dúvida, bastante antigo, remetendo ao período pré-colonial, mas é também fato que a estrutura que hoje lá se encontra, e onde funciona o porto da balsa para a Ilha Comprida, foi construída no final da década de 1920.

O segundo problema está na percepção do território do capital e de seus marcos físicos de construção das paisagens. O capital globalizado e o sistema mundo por ele definido são totalizantes, levando à mercantilização de todas as relações humanas, mas a descontinuidade do espaço físico do planeta e as fronteiras políticas dos Estados Nacionais determinam a conformação de subsistemas ou a dispersão de etapas da produção em regiões distantes dos centros (WALLERSTEIN, 2007). Em termos concretos, para a Arqueologia do Capitalismo, seus objetos de pesquisa estão dispersos por um vasto e descontínuo território ${ }^{4}$. Evidente que não podemos deixar de perceber a nossa própria materialidade com relação às pesquisas desses contextos: há que se ter tempo para estudar todos os aspectos relativos a um meio de produção e a disponibilidade de recursos financeiros para isso.

Como decorrência desta última colocação, constituem-se os espaços portuários como um dos loci privilegiados para o entendimento da produção capitalista a partir da Arqueologia, pois neles há a possibilidade de serem encontrados, com relativa proximidade espacial, contextos arqueológicos que abrangem várias etapas da produção de mercadorias: fabricação e/ou processamento, transporte, comercialização e consumo. Pensando em específico no espaço portuário que envolve a cidade de Cananéia, lá podem ser pesquisados

\footnotetext{
${ }^{4}$ Como exemplo pode-se citar aqueles estudos de Arqueologia ferroviária (notadamente os de contrato, muitos ainda inéditos) que tratam os caminhos de ferro como um meio de produção capitalista (e não como mero patrimônio da era industrial): a pesquisa do bem, na sua totalidade funcional e simbólica, envolveria a análise de edificações, estruturas e equipamentos dispersos por dezenas ou centenas de quilômetros.
} 
naufrágios, estruturas portuárias, estaleiros, engenhos de pilar arroz, fábricas de processamento de pescado, casas comerciais e lixeiras domésticas/comunitárias, todos eles coisas que representam o modo de produção capitalista tal como ele vem se desenvolvendo naquela região e que, em última instância, é a forma de poder que substitui a força (física, bélica) das armas como o mantenedor primaz (não o único) do controle sobre o território e a população, a partir de meados do século XIX ${ }^{5}$.

Com relação ao primeiro problema, a paradoxal monumentalização do antigo e seu uso utilitário atual como situações de turvação da pesquisa arqueológica, foi preciso estudar as etapas de construção das edificações, estruturas e equipamentos, monumentalizados ou ainda em uso, para entender o processo de formação das paisagens marítimas ao longo do oitocentos e do novecentos. E, além de focar nas estruturas portuárias propriamente ditas, aquelas situadas à beira ou dentro d'água, a pesquisa procurou abordar também outros bens que pudessem complementar ou oferecer o contraponto para a contextualização dessas paisagens. Com isso, tentou-se tanto abarcar o maior número de coisas possível daquele espaço portuário quanto buscar informações em fontes aparentemente secundárias, visando à percepção dos discursos, das aparências e das realidades.

As principais edificações, estruturas e equipamentos abordados com esse intuito na pesquisa de doutorado foram o sítio de naufrágio do vapor Conde d'Áquila (1858), os prédios da Câmara Municipal, as indústrias (numa ampla acepção da palavra) e as casas comerciais (independente do produto que comercializavam). Para este artigo, resolvi abordar em detalhes as casas comerciais e sua relação com a evolução portuária de Cananéia, pois: 1) uma das características do modo de produção capitalista no vale do Ribeira é a ênfase na atividade comercial $^{6}$, servindo as localidades da região tanto como entrepostos da produção de arroz (principal produto da região no período em foco) como distribuidores de bens industrializados; 2) as casas comerciais são edificações do espaço portuário de Cananéia, mas

\footnotetext{
${ }^{5}$ A ideia principal, assegurar o poder sem o uso (inicial) de edificações, estruturas e equipamentos que ameacem fisicamente as pessoas (com a morte, em geral), mas sim de bens que simbolizem a coerção moral imposta pelo liberalismo republicano, tem inspiração nas interpretações propostas por Mark Leone e Silas Hurry (1998) sobre, dentre outros sítios, o planejamento urbano das cidades de Saint Mary City (arruinada), Annapolis e Baltimore, ao redor da baía de Chesapeake, no estado de Maryland (EUA).

${ }^{6}$ Em realidade, a importância do comércio seria mais abrangente: a crise do sistema colonial e a constituição da "economia mercantil-escravista cafeeira nacional" reforçaram o caráter mercantil da economia do Estado Nacional brasileiro que surgira no oitocentos (MELLO, 2009:45-49). Contudo, o comércio, assim como a produção industrial tem, de certa forma, um papel diminuído na dinâmica do processo histórico, pois ele é visto como uma atividade inteiramente dependente da grande lavoura. No caso específico de São Paulo, há sensíveis lacunas de estudos históricos sobre a importância dos diferentes grupos de interesse na economia paulista do oitocentos e início do novecentos. As elites acabam sendo tratadas como uma grande camada homogênea, mero reflexo da produção da grande propriedade rural (PERISSINOTTO, 1997). Na Arqueologia, não se deixa de seguir essa tendência, penso eu.
} 
não estão inequivocamente associadas ao mar - estão em terra firme, às vezes, algo distante do meio líquido - o que leva ao motivo 3) demonstrar que o território do capital é descontínuo e que, portanto, não só os naufrágios (submersos) ou as estruturas portuárias (interface terra/água) podem explicar as atividades portuárias; por fim, 4) o estudo das casas comerciais, a partir da Arqueologia, exige a adoção de perspectivas teóricas e metodológicas que não necessariamente envolvem a escavação, mas que demandam o uso de informações provenientes de edificações, estruturas e equipamentos ainda em uso e que não são comumente associadas ao domínio da Arqueologia.

\section{Os portos da cidade de Cananéia}

Será analisada, em exclusivo, uma parcela do imenso espaço portuário ${ }^{7}$ de Cananéia e da zona estuarino-lagunar que a envolve, a saber, aquela que está contígua à zona urbana mais antiga, onde, portanto, ainda hoje ocorre a maior parte das atividades comerciais do município/região.

Retome-se, pois, o caso do porto Bacharel. A designação original, porto 'do' Bacharel, foi legada à estrutura em 1931 (ALMEIDA, 1964:502). Ele é tido como "o" porto ancestral de Cananéia, mas a realidade é mais complexa: embora esse porto esteja no centro da cidade e seja utilizado há muito tempo, isso de acordo com os vestígios nele localizados em $2007^{8}$, sua forma atual se originou a partir da união de outros dois cais de alvenaria de pedra: o do Mercado, construído em data incerta (séculos XVIII-XIX), e o Municipal ou Grande, concluído em 1889 (ALMEIDA, 1961:480). O primeiro definiu o limite sul do novo porto; o segundo, os limites norte e leste, o que formou o polígono regular ainda hoje visível, embora parcialmente encamisado por concreto armado. E, onde atualmente estão os flutuantes da balsa, foram construídas, logo após a conclusão do cais de pedra, no fim da década de 1920 (1927-1929), duas pontes de madeira para facilitar o embarque e desembarque em navios maiores. Foi também nessa década que se criou uma rampa pavimentada ao sul do porto, a qual passou a formar um sistema de circulação em conjunto com a rampa norte, mais antiga e parte da estrutura do cais Municipal.

\footnotetext{
${ }^{7}$ Entende-se espaço portuário como sendo um local de contato entre a embarcação e a terra, não importando se há estruturas específicas para a aportagem, ou se a embarcação será varada, ou se haverá transbordo (BLOT, 2003:32-33). Ou seja, o conceito se refere a uma sucessão de paisagens e não a um equipamento específico (um cais de pedra, por exemplo).

${ }^{8}$ Em prospecção realizada no aterro do porto, em 2007, foi encontrada cerâmica com decoração corrugada, possivelmente indígena, além de faiança ibérica. Também foi identificada uma rampa de embarque e desembarque, pavimentada com uma argamassa de terra e conchas (BAVA-de-CAMARGO, 2009:111-122).
} 
O porto do Bacharel representa, portanto, a etapa final de concentração do fluxo portuário. Depois disso, o movimento de navios foi diminuindo de forma drástica até 1942, quando se tem notícia da entrada do último vapor de cabotagem no porto de Cananéia (ALMEIDA, 1961:476). Após essa data, o transporte de e para Cananéia ficou condicionado ao modal rodoviário e hidroferroviário, modificando a estrutura de circulação de mercadorias e, como consequência, o controle sobre ela.

A etapa inicial de concentração das atividades portuárias se deu com a construção do cais Municipal, mas, naquela época, 1885-1889 (BAVA-de-CAMARGO, 2009:86-87), havia outros portos, no núcleo urbano, com importante papel para a circulação de pessoas e mercadorias 9 .

A construção do cais Municipal ocorreu diante da necessidade de melhorar as condições de atracação dos navios a vapor presentes no espaço portuário de Cananéia desde a década de 1850, como nos revela o sítio arqueológico de naufrágio do Conde d'Áquila, navio afundado em 1858, a poucos metros da costa (RAMBELLI, 2003).

Antes do cais Municipal, os navios a vapor, assim como diversas outras embarcações, eram fundeados próximos à praia e ao barranco onde hoje está o cais de saneamento e passeio público da Avenida Beira Mar (AVÉ-LALLEMANT, 1980:310). Não havia um local específico para embarque e, portanto, não havia concentração das atividades portuárias.

E antes do advento da navegação a vapor, a principal área de fundeio ficava à sombra do morro São João, em frente à foz do rio Olaria. Abrigada dos ventos do quadrante sul, tendo lenha e água em quantidade e com boa profundidade para embarcações de menor porte, tais como lanchas e sumacas - aquelas que efetivamente tocavam o porto de Cananéia antes da segunda metade do século XIX - a área ficava próxima ao estaleiro do capitão-mor Joaquim José da Costa, no local onde hoje está instalada a base do Instituto Oceanográfico da USP, submetida à prospecção em 2007 (BAVA-de-CAMARGO, 2009; 2008). Como não havia um atracadouro específico, nem uma embarcação de grande capacidade que polarizasse todo o transporte de mercadorias, o fluxo portuário era pulverizado pela costa do núcleo urbano, nas margens do rio Olaria e do riacho Ipiranga ${ }^{10}$ que cortava a povoação no sentido norte sul.

\footnotetext{
${ }^{9}$ Como o porto do Rosário, bastante profundo e estabelecido no término/ início do caminho que levava ao outro lado da ilha, ao Itapitangui, à estação telegráfica e à colônia Cananéia (BAVA-de-CAMARGO, 2009:90).

${ }^{10}$ Segundo A. P. de Almeida, no riacho Ipiranga, também conhecido como a "piranga", teria se situado o "porto dos Bugres", nome popular dado a um ancestral embarcadouro (1964:443-444). O mesmo autor conta que, às margens do riacho haviam sido encontrados cabos náuticos que seriam bastante antigos.
} 
Enfim, reportando novamente à tese, uma das conclusões às quais se chegou foi de que esse papel de primazia do porto do Bacharel representa o final de um processo econômico, hoje cristalizado como um destino manifesto, sacralizado e naturalizado em razão da exaltação à figura do Bacharel quinhentista. O que ocorreu foi o deslocamento do centro das atividades portuárias, a partir de meados do século XIX, e até meados do século XX, das faldas do morro São João para o porto do Bacharel, em função das mudanças impostas pela cabotagem a vapor e da necessidade de controle daquela época. Tanto é assim que, hoje, o porto Bacharel não é mais o centro das atividades náuticas da região. Continua sendo importante, pois a balsa para Ilha Comprida funciona nele. Mas, a pesca comercial, a qual tem necessidades portuárias específicas e que é atualmente a maior indústria de Cananéia, saiu do antigo cais do Mercado e migrou para a foz do rio Olaria, à sombra do morro São João, tal como faziam as antigas embarcações a vela e as canoas, tornando aquela área um polo de concentração de riqueza e de controle sobre a produção, tendo diversas empresas e a Ceagesp se instalado lá. Já o pólo de concentração das atividades de turismo náutico, outro componente da produção contemporânea de Cananéia, situa-se atualmente no píer da Prefeitura, em lado diametralmente oposto às atividades de pesca, em frente à edilidade e mais próximo das pousadas (para mais referências ver BAVA-de-CAMARGO, 2009: 63-79).

O que se vê, então, é uma relação de determinação entre as funções portuárias e o core da atividade que necessita daquela edificação, estrutura ou equipamento, razão esta que ajuda a estruturar a continuidade deste trabalho.

\section{A dinâmica das casas comerciais a partir da evolução de suas fachadas}

A premissa para esta parte do estudo é bastante simples: se foi observada uma gradual concentração das atividades portuárias na estrutura do porto do Bacharel, haveria a possibilidade de enxergar esse processo de concentração em outras edificações, estruturas e bens do espaço marítimo. Para identificar isso, realizou-se um levantamento das edificações, entes e feições urbanas atuais, o qual foi correlacionado a plantas, mapas e fotografias $\operatorname{antigas}^{11}$, permitindo estabelecer uma escala cronológica e espacial para a evolução das fachadas. Essas informações sobre Cananéia foram então inseridas em uma carta analítica, a qual permitiu o entendimento da evolução da cidade.

\footnotetext{
${ }^{11}$ Fotos datadas entre 1906 e 1936, do acervo do projeto "Museu de Rua", desenvolvido nos anos 80 pelo Condephaat e hoje sob os cuidados do escritório de Julio Abe Wakahara.
} 
A metodologia para a realização desse tipo de levantamento em estudos arqueológicos tem origem na Arqueologia Extensiva. Está-se, assim, trabalhando com uma interface entre a Arquitetura, História, Geografia e Arqueologia, na qual todas as informações são incorporadas a uma mesma base de dados, sem privilégio do registro arqueológico (ruínas, jazimentos) sobre as demais fontes de informação (JIMÉNEZ PUERTAS, 2006).

E como identificar quais edificações teriam sido construídas ou reformadas para serem casas comerciais? Baseando-se num padrão estabelecido pelo Condephaat ${ }^{12}$ quando iniciou suas atividades na região, c. 1970 (ROCHA FILHO, 2005). De maneira geral, edificações cujas envasaduras das fachadas eram todas portas teriam servido como casas comerciais, de serviços ou industriais (pois essas atividades ocasionavam grande circulação de pessoas e de mercadorias volumosas). Este seria o caso das edificações térreas. As edificações com mais de um piso, cujo primeiro andar só apresentasse portas, seriam consideradas de uso misto, com morada em cima e comércio embaixo. Todavia, estabeleceuse uma variação nesse padrão: também foram consideradas de uso misto edificações térreas que apresentassem mais de uma porta nas fachadas, pois assim os pequenos negócios também seriam registrados.

Para excluir as fachadas do comércio contemporâneo da base de dados, só foram registradas as edificações construídas com alvenaria de pedra, ação que permitiu a avaliação do período desejado (c.1880-1930). Isso foi possível porque edificações inteiramente de alvenaria de tijolo eram pouco comuns até a década de 1920, quando se instalou na cidade uma olaria para a produção de tijolos em grande escala (ALMEIDA, 1965:470), provavelmente em razão da demanda por tijolos gerada pela serraria e fábrica de barris.

O resultado dessa análise pode ser visto na Prancha 1 (em anexo), na qual estão evidenciadas as edificações que tinham funções comerciais e industriais na década de 1920 e aquelas que haviam deixado de ser comerciais até aquela década ${ }^{13}$. Assim, foi possível perceber alguns locais de concentração das edificações das estruturas produtivas, totalizando 9 áreas, em verde.

A Área 1 é a principal. A ela voltar-se-á mais adiante. Note-se, em primeiro lugar, aquelas que não são o foco central desta análise: as Áreas 3, 4 e 5 não estariam, em princípio,

\footnotetext{
${ }^{12}$ Conselho de Defesa do Patrimônio Histórico, Arqueológico, Artístico e Turístico, órgão da Secretaria de Estado da Cultura de São Paulo.

${ }^{13} \mathrm{~A}$ percepção dessa mudança foi possível graças à comparação entre as fotos do acervo do Museu de Rua. Algumas delas foram tiradas de ângulos muito semelhantes, por vários anos seguidos. Assim, comparando as sequências de fotos foi possível perceber que algumas das edificações que tinham mais de uma porta em suas fachadas, antes dos anos 20 ou no começo dos anos 20 , possuíam apenas uma porta no final daquela década ou começo da seguinte.
} 
diretamente relacionadas ao meio marítimo, mas sim à circulação terrestre e ao adensamento urbano.

A Área 3 estaria associada não a um porto, mas a uma área de convergência de caminhos terrestres: o caminho mais antigo, que seguia do porto do Rosário, passava pelo cemitério e chegava do outro lado da ilha; e a estrada, caminho novo estabelecido ao longo da linha telegráfica, eixo da atual Avenida Independência. Essa concentração de pequenas casas comerciais, armazéns e botequins, que talvez não estivesse diretamente relacionada à comercialização da produção do arroz, ficavam em encruzilhada "seca", próxima de bairros tais como o Acaraú e Rocio.

Há algumas edificações dispersas pela altura da Rua Tristão Lobo com a Rua Pedro Correa, as quais foram aglutinadas na Área 4. Esse fato não pode ser explicado pela proximidade da área com os portos marítimos, mas pela densidade de edificações da rua, afinal, seria bastante cômodo para os moradores disporem de comércio nas proximidades de suas casas e não só em áreas relativamente distantes.

Já a Área 5 poderia eventualmente estar associada ao uso do riacho Ipiranga como via de deslocamento das mercadorias em canoas, na maré alta, mas isso é muito difícil de definir sem escavações específicas ou levantamentos minuciosos em arquivos.

Com relação às áreas fabris isoladas do núcleo urbano principal - Áreas 2, 8 e 9 todas estavam relacionadas às atividades de processamento de madeira. As Áreas 8 e 9 eram estaleiros: a 8 representa dois estaleiros de embarcações pesqueiras e de carga e a 9, no sopé do morro São João, era referente ao estaleiro desativado do capitão mor Joaquim José da Costa. A Área 2 foi definida no local da serraria e fábrica de barris, empreitada iniciada nos anos 1920 (1923), com capital de investidores de fora de Cananéia, píer de embarque privativo com grua manual para carga e descarga e produção destinada a outras praças, inclusive a Argentina (barris para armazenamento de vinho, segundo SANTOS, 1952:71).

Retornando à Área 1, é interessante notar que, mesmo nessa região, no coração do núcleo urbano original, muitas das casas com fachadas comerciais já não mais cumpriam essas funções na década de 1920, tais como as que estão na extremidade norte do flanco leste da Rua Bandeirante, além daquelas que estão na esquina da Rua Pero Lopes (Área 1C). Parece que, na verdade, o comércio, na Área 1, estava com uma dinâmica reduzida, muito embora as obras portuárias e o fluxo de embarcações demonstrassem seguir na direção contrária. 
O que parece ter ocorrido nessa época é a redução da quantidade de casas comerciais e a concentração dos negócios entre os dois engenhos a vapor da cidade ${ }^{14}$, as duas edificações que estão pintadas em vermelho e roxo: uma na Rua Bandeirante, outra na Avenida Beira Mar. Esses empreendimentos fabris estavam ambos próximos do cais Municipal, com nítidas vantagens para o engenho do norte, antes de 1929: enquanto esse estava a $60 \mathrm{~m}$ do cais, o do sul estava a $90 \mathrm{~m}$. Entretanto, com a construção da rampa sul do porto do Bacharel e a união entre o cais do Mercado e o Municipal, entre 1927-1929, ambos os engenhos ficaram equidistantes do porto principal, uma relação espacial que não parece nada casual. Há que se ter em mente que, o transporte entre os engenhos e o cais era feito por carregadores descalços, os quais recebiam por saca conduzida (SANTOS, 1952). Assim, antes do porto do Bacharel, o engenho do sul teria que dispor de $33 \%$ mais carregadores para conduzir ao cais a mesma quantidade de carga que seria transportada, no mesmo espaço de tempo, a partir do engenho do norte.

Outro fator que pode ter contribuído para o fechamento de casas comerciais nos anos 1920, a despeito de outros indicadores apontarem para uma maior dinâmica na economia, foi o fato de que esses engenhos urbanos de descascar arroz eram movidos a vapor; portanto, tinham grande capacidade de processamento.

Anteriormente à existência dos engenhos a vapor no núcleo urbano, o arroz produzido tanto pelos grandes quanto pelos pequenos produtores era beneficiado em engenhos distantes da vila, movidos à água. Cada engenheiro - designação dada ao dono do engenho - poderia eventualmente escolher a representação comercial na sede do município que mais lucro lhe propiciasse, o que garantiria a existência de certo número de casas comerciais. Não sendo o beneficiamento do arroz concentrado, não seria provável a existência de uma comercialização também concentrada e haveria mais espaço para a aferição de lucro com a comercialização do produto.

Com o advento dos engenhos a vapor no distrito sede, a produção do arroz passa a ser beneficiada muito próxima ao local do embarque, dispensando o serviço dos engenheiros rurais, que também atuavam como concentradores da produção dos locais mais distantes (PETRONE, 1966). Embora as relações entre produtores e beneficiadores de arroz ainda seja pouco compreendida, é certo que a eliminação de intermediários garantiria maiores lucros para as duas pontas do processo - lavradores e agentes comerciais do centro urbano.

\footnotetext{
${ }^{14}$ Não é possível precisar quando surgiram os primeiros engenhos movidos a vapor em Cananéia. Segundo o que se depreende de M. H. Santos (1952), isso teria ocorrido entre os últimos anos do século XIX e os primeiros do século XX.
} 
Deve-se notar, entretanto, que com a eliminação de alguns dos intermediários na cadeia produtiva, haveria uma tendência de contato direto entre lavradores e os engenheiros do centro urbano, praticamente eliminando as possibilidades de negócios para pequenos comerciantes. Reflexo dessa concentração em curso ou uma das causas dela é a retificação e consolidação do talude da fachada marítima de Cananéia, ocorrida em concomitância com a construção do porto do Bacharel, na década de 1920. Nessa época, o talude existente na atual Avenida Beira Mar, antiga Rua Dr. Alcoforado, começou a ser revestido com uma muralha de pedra, dando origem ao cais de saneamento ainda hoje visível na orla. Essa muralha dificultou ou praticamente eliminou as possibilidades de carga e descarga de mercadorias na vasta fachada marítima, condicionando essas operações, a partir das canoas, à varação das mesmas nas proximidades do porto do Bacharel ou a uma viela diante do engenho do sul. Não é possível determinar se essas canoas de carga conseguiriam adentrar pela foz do rio Olaria, a esta época parcialmente obstruída pelos pilares da ponte antiga. Assim, o saneamento da orla de Cananéia levou a uma concentração também das remessas de arroz a partir dos produtores. Até o final da década de 1920, a chegada do produto ao núcleo urbano era dispersa, pois cada agricultor trazia a sua produção ou a de um coletivo de produtores (PETRONE, 1966) em grandes e robustas canoas de carga, as quais encostavam nos barrancos, praias ou adentravam pelos cursos d'água; só a exportação da mercadoria era concentrada nos vapores marítimos e, em menor escala, nos fluviais. Como eram os próprios agricultores que deveriam levar seu produto até os negócios, a proximidade entre o porto e o comércio era bastante necessária. Assim, o comerciante precisava estar o mais próximo possível da área de descarga das canoas. Como todo o talude da Beira Mar era propício para a varação de canoas, dependendo da maré, não havia motivo para a concentração de casas de comércio. Já com a construção do cais de saneamento, essa relação se tornou mais complicada, pois o cais bloqueava o acesso dos agricultores/canoeiros às ruas, podendo ser essa uma das explicações do porque das edificações da Subárea $1 \mathrm{C}$ terem deixado de ter funções comerciais, nos anos 20, uma vez que ficaram com o acesso muito mais difícil ao mar.

Finalmente, há as indicações de edificações que foram estruturas produtivas, mas que, na década de 1920, não podiam ser consideradas ativas (Áreas 6 e 7). Essas áreas se localizavam próximas às extremidades da Rua Capitão Ernesto Martins Simões, na margem norte do rio Olaria, a leste e a oeste do riacho Ipiranga.

A implantação dessas casas comerciais pode explicar-se pela utilização do riacho Ipiranga e do rio Olaria como vias de comunicação com o mar. No caso da Área 7, ela 
também teria comunicação direta com o mar, através da baixada que hoje é ocupada pela Ceagesp. Nessa última área há um controle visual bastante eficaz do fluxo portuário proveniente do rio Olaria e das embarcações que fundeiam à sombra do morro São João. Na Área 7, a câmara municipal teria ocupado a maior das casas antes de 1860 (ALMEIDA, 1965:465); estava ela localizada diante daquele que havia sido o principal fundeadouro de embarcações antes do início da navegação a vapor. Assim, é de se supor que a câmara só tenha mudado para o local onde ela hoje se encontra em razão de uma drástica mudança no padrão de aportagens. Esta, só aconteceu com o predomínio da cabotagem a vapor.

Além do deslocamento das atividades portuárias para o talude da atual Avenida Beira Mar e a posterior mudança delas para o cais Municipal, outro fator que pode explicar a desaparição dessas zonas comerciais é o assoreamento dos cursos d'água doce/salobra, bem como da fachada marítima contígua à desembocadura do rio Olaria. Embora faltem dados geofísicos/oceanográficos, esse acúmulo de sedimentos, principalmente na Área 7, pode ter sido causado por uma das fases construtivas da ponte sobre o rio Olaria e pela construção do próprio cais Municipal, ambas obras que teriam afetado a dinâmica sedimentar marítima na costa contígua à cidade.

\section{Considerações finais}

Essa discussão está longe de ser encerrada, pois a centelha que desencadeou a concentração dos meios de produção e, consequentemente, do controle sobre esses meios de produção, na segunda metade do século XIX, mantém-se viva na nossa sociedade. Seria tema bastante profícuo o entendimento das transformações da base da economia de Cananéia e do vale do Ribeira, a partir da segunda metade do século XX, pois, a despeito do discurso generalizado da pobreza da região, a Cananéia do arroz se transformou na da pesca e do turismo... e há gente ganhando dinheiro com isso; o grande problema continua sendo a distribuição da riqueza. Essas atividades, hoje levadas a cabo em grande escala, necessitaram de capitais externos e do capital local acumulado com a rizicultura, tendo-se valido, também, da estrutura portuária preexistente como um dos meios de produção. Assim, quando se diz que a cabotagem a vapor encerrou na década de 1940, isso não significa que as paisagens desse espaço portuário tenham entrado em decadência e se cristalizado como monumentos históricos: elas foram, são e serão reapropriadas e modificadas pelo transporte hidroferroviário (também não mais existente), pelas atividades pesqueiras, pelo discurso 
historicista e pelo turismo náutico. E, embora a fruição dessas paisagens flúvio-marítimas tenha sido universalizada pela ideia de democratização e pluralização da sociedade contemporânea, elas continuam a ser paisagens de concentração de capital, controle e exclusão social. Talvez potencializadas, até: basta uma volta pela orla da cidade, desde o morro São João até o extremo norte da Avenida Beira Mar, com uma pergunta em mente “em quais pontos da costa eu poderia embarcar ou desembarcar livremente?" - para se perceber que o acesso real ao mar é muito menor do que o imaginado.

\section{Referências bibliográficas}

ALMEIDA, Antonio P. Memória Histórica de Cananéia (X). Revista de História, São Paulo (FFLC-USP), vol. 31, nº. XX, p. 453-477, 1965.

. Memória Histórica de Cananéia (VII). Revista de História, São Paulo (FFLCUSP), vol. 28, nº. 58, p.483-504, 1964.

. Memória Histórica de Cananéia (V). Revista de História, São Paulo (FFLC-USP), vol. $\overline{25, n^{\circ}} .51, p .192-217,1962$.

. Memória Histórica de Cananéia (II). Revista de História, São Paulo (FFLC-USP), vol. $22, n^{\circ} .46, p .191-237,1961$.

. Memória Histórica de Cananéia (II). Revista de História, São Paulo (FFLC-USP), vol. $\overline{22, n^{\circ} .45, p .475-520,1961 .}$

. História da navegação no litoral paulista. Revista do Arquivo Municipal, São Paulo, ano XIX, vol. CLIII, novembro, 1952.

AVÉ-LALLEMANT, Robert. Viagens pelas províncias de Santa Catarina, Paraná e São Paulo (1858). B. Horizonte/ S. Paulo: Itatiaia/ Edusp, 1980.

BAVA-de-CAMARGO, Paulo F. Arqueologia de uma cidade portuária: Cananéia, séculos XIX-XX. São Paulo, 2009. Tese (Doutorado em Arqueologia) - Museu de Arqueologia e Etnologia, Universidade de São Paulo, 2009.

. Prospecção arqueológica na base costeira do Instituto Oceanográfico da USP em Cananéia, estado de São Paulo. Revista do Museu de Arqueologia e Etnologia, São Paulo, 18, 2008. P.323-330.

. Arqueologia das fortificações oitocentistas da planície costeira Cananéia/ Iguape, SP. São Paulo, 2002. Dissertação (Mestrado em Arqueologia) - Faculdade de Filosofia, Letras e Ciências Humanas, Museu de Arqueologia e Etnologia, Universidade de São Paulo, 2002. 
BLOT, Maria L. B. H. P. Os portos na origem dos centros urbanos: contributo para a arqueologia das cidades marítimas e flúvio-marítimas em Portugal. Lisboa: Instituto Português de Arqueologia, 2003. Série Trabalhos de arqueologia, nº 28.

JIMÉNEZ PUERTAS, Miguel. Historia y Arqueología de los paisajes rurales: un proyecto de presente y de futuro para el territorio de Loja. Arqueología Medieval.com. Publicado em 24/07/2006. URL: http://www.arqueologiamedieval.com/articulos/79/historia-y-arqueologiade-los-paisajes-rurales-un-proyecto-de-presente-y-de-futuro-para-el-territorio-de-loja.

Acessado em 24/01/2013.

LEONE, Mark P.; HURRY, Silas D. Seeing: the power of town planning in Chesapeake. Historical Archaeology, Tucson, vol. 32, nº. 4, p.34-62, 1998.

MELLO, João M. C. O capitalismo tardio. São Paulo/ Campinas: Editora UNESP/ FACAMP, 2009. $11^{\mathrm{a}}$. edição.

PERISSINOTO, Renato M. Classes dominantes, Estado e os conflitos políticos na Primeira República em São Paulo: sugestões para pensar a década de 1920. DE LORENZO, H. C.; COSTA, W. P. A década de 1920 e as origens do Brasil moderno. São Paulo: Editora da UNESP, 1997. P.37-69.

PETRONE, Pasquale. A Baixada do Ribeira: estudo de geografia humana. São Paulo: FFLCH/USP, 1966.

RAMBELLI, Gilson. Arqueologia subaquática do baixo vale do Ribeira, SP. São Paulo, 2003. Tese (Doutorado em Arqueologia) - Museu de Arqueologia e Etnologia, Universidade de São Paulo, 2003.

ROCHA FILHO, Gustavo N. Cananéia: levantamento sistemático destinado a inventariar bens culturais do estado de São Paulo. São Paulo: Condephaat, 2005. $2^{\mathrm{a}}$. edição.

SANTOS, Manoel H. A cidade esquecida. Boletim do Departamento de Arquivo do Estado, São Paulo, 1952, vol. 9, p.51-138, 1952.

WALLERSTEIN, Immanuel. Capitalismo histórico \& Civilização capitalista. Rio de Janeiro: Contraponto, 2007. 


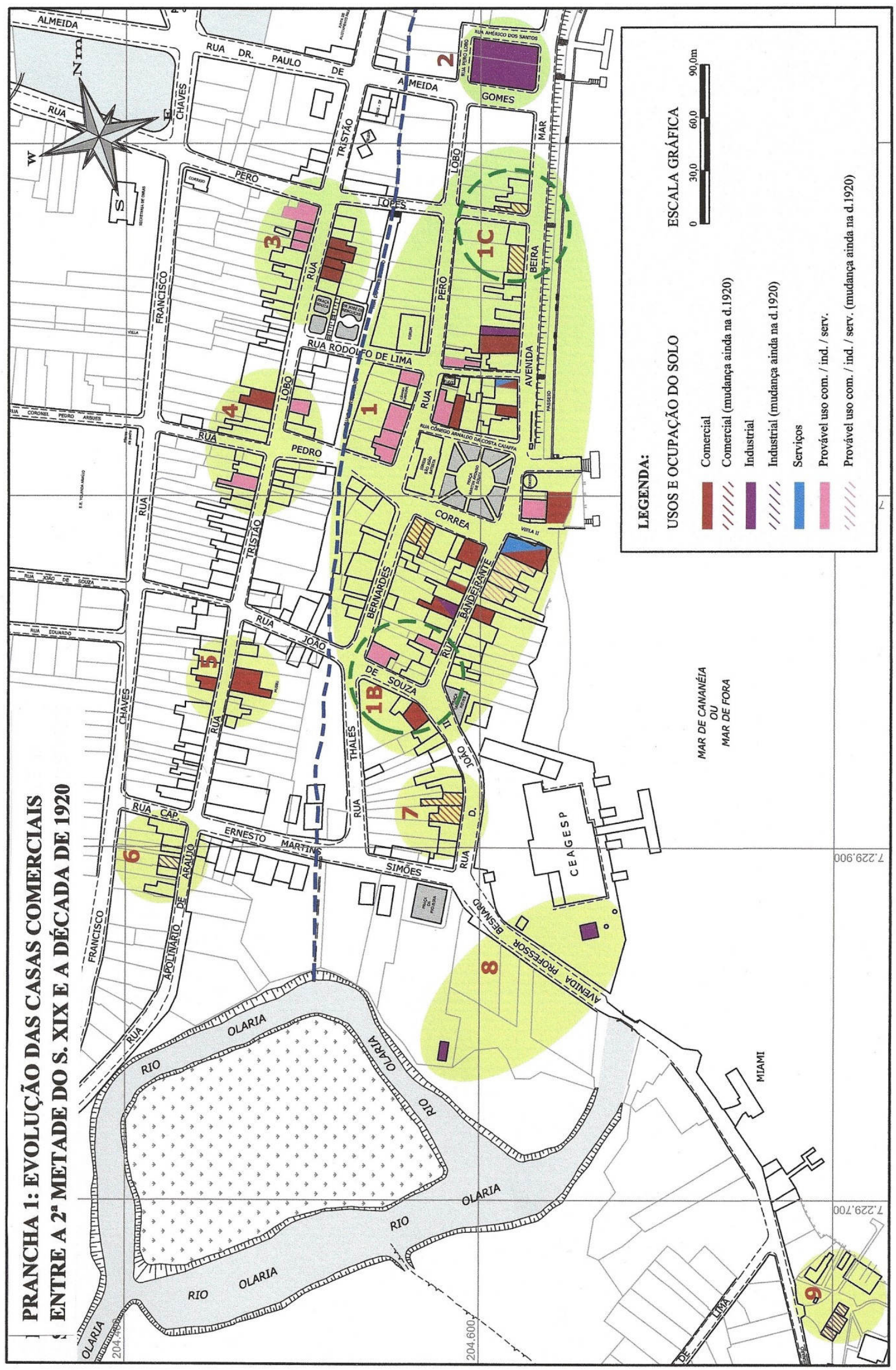

